\title{
Diaphragm fatigue during exercise at high altitude: the role of hypoxia and workload
}

\author{
M. Gudjonsdottir*, L. Appendini”, P. Baderna", A. Purro", A. Patessio", G. Vilianis", \\ M. Pastorelli ${ }^{\star}$, S.B. Sigurdsson*, C.F. Donner ${ }^{\#}$
}

\begin{abstract}
Diaphragm fatigue during exercise at high altitude: the role of hypoxia and workload. M. Gudjonsdottir, L. Appendini, P. Baderna, A. Purro, A. Patessio, G. Vilianis, M. Pastorelli, S.B. Sigurdsson, C.F. Donner. (C) ERS Journals Ltd 2001.

ABSTRACT: The effect of high altitude (HA) on exercise-induced diaphragm fatigue in normal subjects was examined.

Eight normal subjects completed an incremental exercise test at sea level (SL) and at $3,325 \mathrm{~m}$. Before (baseline), during, and after exercise (recovery), maximal transdiaphragm pressure ( $P$ di,sniff), breathing pattern, and diaphragmatic effort (PTPdi) were measured. Arterialized blood lactate was measured at baseline and during recovery.

At maximal exercise (WRmax) $P$ di,sniff fell to $72 \%$ and $61 \%$ of baseline at SL and $H A$ respectively, recovering to baseline in $60 \mathrm{~min}$ at $\mathrm{SL}$, and $>60 \mathrm{~min}$ at $\mathrm{HA}$. At the 5th $\mathrm{min}$ of recovery, circulating lactate was six-fold and seven-fold baseline at SL and HA, respectively. The time course of circulating lactate recovery was as for $P$ di,sniff. At WRmax PTPdi was 80.74 $\pm 9.87 \mathrm{kPa}^{-1} \mathrm{~s}^{-1}$ at $\mathrm{SL}$ and $64.13 \pm 8.21 \mathrm{kPa}^{-1} \mathrm{~s}^{-1}$ at HA. HA WRmax compared to isowork rate, $\mathrm{SL}$ data showed a lower $P$ di,sniff $(8.90 \pm 0.68$ versus $11.24 \pm 0.59 \mathrm{kPa})$ and higher minute ventilation $\left(117 \pm 11\right.$ versus $\left.91 \pm 13 \mathrm{~L} \cdot \mathrm{min}^{-1}\right), \mathrm{PTPdi}$ being equal.

To conclude, in normal subjects hypoxia-related effects, and not an increase in diaphragm work, hastens exercise-induced diaphragm fatigue and delays its recovery at high altitude compared to sea level.

Eur Respir J 2001; 17: 674-680.
\end{abstract}

\begin{abstract}
*Dept of Physiology, University of Iceland, Reykjavik, Iceland. " Division of Pulmonary Disease, Salvatore Maugeri Foundation, IRCCS, Rehabilitation Institute of Veruno, Italy. Intensive Care Unit, Edoardo Agnelli Hospital, Italy.
\end{abstract}

Correspondence: L. Appendini, Fondazione Salvatore Maugeri, Clinica del Lavoro e della Riabilitazione, IRCCS, Instituto di Riabilitazione di Veruno, Divisione di Pneumologia, Via per Revislate 13, I-28010 Veruno, Italy. Fax: 390322830294

Keywords: Diaphragm fatigue, exercise testing, hypoxia, respiratory mechanics, respiratory muscles

Received: March 272000

Accepted after revision November 23 2000
Exercise limitation at high altitude (HA) has been extensively studied using sophisticated techniques (Swan-Ganz catheterization, inert gas diffusion, etc.) $[1,2]$. However, data concerning respiratory muscle function are scanty nevertheless, exercise on either cycle-ergometer or treadmill at sea level (SL) has been shown to produce diaphragm fatigue in healthy subjects [3-6] as measured with volitional (Mueller and sniff) [3, $4,6]$ and objective (bilateral phrenic nerve stimulation; BPNS) manoeuvres [3-6]. Therefore, the aim was to investigate exercise-induced diaphragm fatigue at HA. HA might well resemble normobaric hypoxia which is known to hasten diaphragm fatigue during exercise [3]. However, at HA the density of air decreases, resulting in decreased airway flow resistance [7] and reduced work of breathing. The authors sought to identify possible different physiological responses to exercise at HA compared to normobaric hypoxia [3].

\section{Methods}

\section{Subjects}

Eight healthy male subjects (age $38 \pm 2$ yrs) born and living at SL, not acclimatized to HA, gave their consent to perform the study.

\section{Measurements}

Flow $\left(V^{\prime}\right)$ was measured with a mass flow sensor (Sensormedics, Yorba Linda, CA, USA) and volume $(V)$ was obtained by integrating the flow signals. The mass flow sensor was calibrated with a $3 \mathrm{~L}$ syringe before each test.

Oesophageal $\left(P_{\text {oes }}\right)$ and gastric $(P$ ga $)$ pressure changes were measured as previously reported [8]. Airway opening pressure $(P$ ao $)$ was measured via a side-port placed on a two-way breathing valve (720068, Jaeger, Würzburg, Germany) connected to the mass flow sensor. Transpulmonary $\left(P_{\mathrm{L}}\right)$ and transdiaphragmatic $(P$ di) pressures were obtained by subtracting $P$ oes from $P$ ao and $P$ ga, respectively. $P \mathrm{~L}, V^{\prime}$ and $V$ data were used to calculate dynamic lung elastance $(E \mathrm{~L}$,dyn) and lung resistance $(R \mathrm{~L})$ [9].

Maximal oesophageal and transdiaphragmatic pressures were measured with the Mueller [10] ( $P_{\text {oes,max }}$ and $P$ di,max, respectively) and the sniff $[10]$ (Poes,sniff and $P$ di,sniff, respectively) manoeuvres. End-expiratory lung volume (EELV) before sniffs was monitored using end-expiratory $P_{\text {oes }}[11,12]$. To assess diaphragmatic length, $P$ ga was continuously monitored [11]. Criteria for accepting and correcting $P$ oes,sniff for abdominal muscle contractions ( $P$ oes,sniff corr) were those described by KYroussis et al. [12]. The sniff showing the greatest 

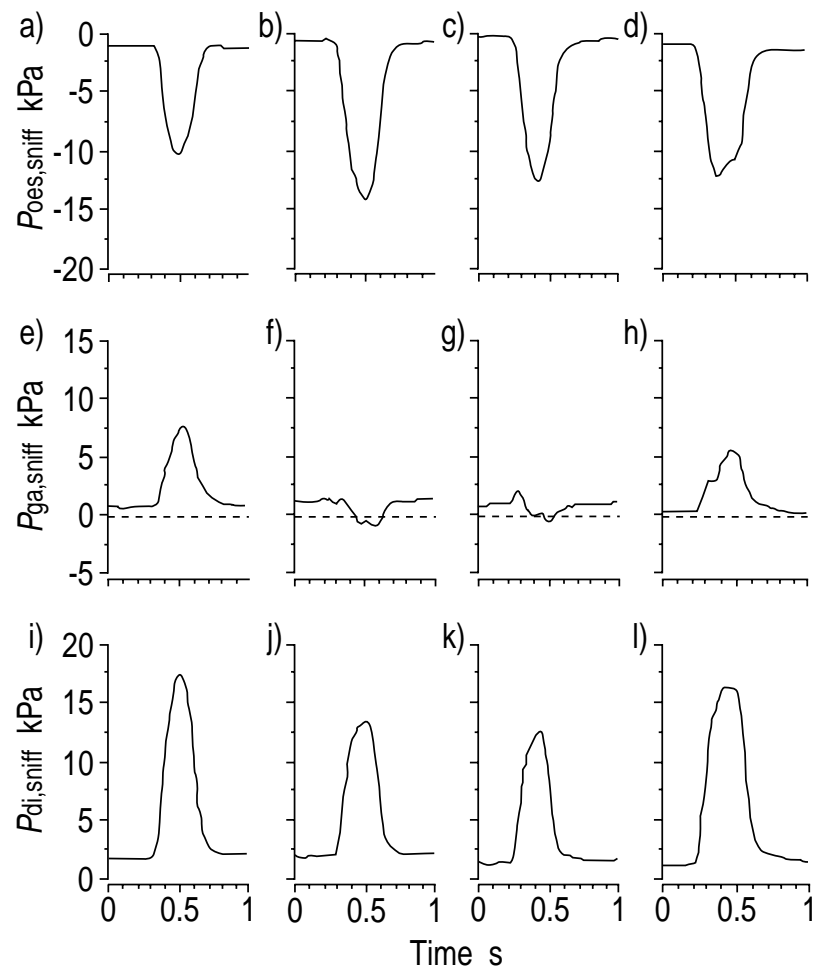

Fig. 1. - Representative recordings of maximal inspiratory pressures measured with the sniff manoeuvre in subject 6 at SL. a-d) maximal inspiratory oesophageal $\left(P_{\text {oes,sniff }}\right)$, e-h) gastric $\left(P_{\text {ga,sniff }}\right)$ and i-l) transdiaphragmatic ( $P$ di,sniff $)$ pressures, measured at baseline (a, e, i), maximal exercise $(b, f, j)$, and at the 1 st min (c, g, $\mathrm{k})$ and 60 th $\mathrm{min}$ of recovery $(\mathrm{d}, \mathrm{h}, \mathrm{l})$.

pressure deflection in each condition and fulfilling all criteria [12] was selected for analysis. Figure 1 shows a representative record of sniffs during the protocol.

To estimate the diaphragmatic and respiratory muscle effort, the pressure-time product for diaphragm (PTPdi) and respiratory muscles (PTPoes) over $1 \mathrm{~min}$ were computed [8]. Since diaphragm external work rate $\left(\mathrm{W}^{\prime} \mathrm{di}\right)$ has been shown to be a better index of diaphragm effort than PTPdi when inspiratory flow is not constant [13], the former was also computed, by multiplying PTPdi by the actual mean inspiratory flow [13].

Oxygen consumption $\left(V^{\prime} \mathrm{O}_{2}\right)$, and carbon dioxide production $\left(V^{\prime} \mathrm{CO}_{2}\right)$ were measured breath-by-breath (Vmax29; Sensormedics, Yorba Linda, CA, USA). Gas analysers were calibrated before each test. Heart rate (HR) was measured from a 12-lead electrocardiogram.

Arterialized venous blood [14] was obtained to estimate $\mathrm{Pa}, \mathrm{CO}_{2}$ (ABL 300; Radiometer, Copenhagen, Denmark) and measure lactate (2300 STAT; Yellow Spring Instrument, Yellow Spring, $\mathrm{OH}$, USA). $\mathrm{Pa}, \mathrm{CO}_{2}$ and barometric pressure $\left(P_{\mathrm{B}}\right)$ were used to calculate the alveolar oxygen partial pressure $\left(P \mathrm{~A}, \mathrm{O}_{2}\right)[15]$. A finger oximeter (BIOX 3760; Datex-Ohmeda, Division Instrumentarium Corp., Helsinki, Finland) measured arterial $\mathrm{O}_{2}$ saturation $\left(\mathrm{Sa}, \mathrm{O}_{2}\right)$.

\section{Protocol}

Measurements were performed at baseline, during an incremental exercise test to volitional tolerance on cycle-ergometer (Ergo-metrics 800S; Sensormedics, Yorba Linda, CA, USA) and during the hour after exercise. The protocol was performed both at 3,325 m of altitude (Rifugio Torino, Monte Bianco, Italy) and at SL. At $\mathrm{HA}, P_{\mathrm{B}}$ and resting $P \mathrm{~A}, \mathrm{O}_{2}$ were $66.93 \pm 0.14$ and $7.60 \pm 0.27 \mathrm{kPa}$ respectively. At $\mathrm{HA}$, the subjects were studied within a few hours of the ascent (cableway), sitting on the cycle-ergometer with the thorax kept in the same position throughout the study.

Baseline measurements. Before exercise, spirometry showed normal values [16] in every instance. The sniff and Mueller manoeuvres were practised until both appeared reproducible $( \pm 5 \%)$ and fulfilled all inclusion criteria. Then subjects started to breathe through the mouthpiece until they felt comfortable with the measurement apparatus. At this point, breathing pattern was recorded for $1 \mathrm{~min}$, followed by measurements of HR, blood samples, and maximal inspiratory pressures.

Exercise. After 3 min of unloaded pedalling, the work rate (WR) was increased by $20-30 \mathrm{watts}^{\mathrm{min}} \mathrm{m}^{-1}$ to volitional tolerance and/or until maximal predicted HR (220 - age) was reached [15]. Incremental loads differed between subjects to keep the exercise within 10 min [15]. In the last $30 \mathrm{~s}$ of unloaded pedalling and between the 30th and 45th second of every minute during exercise, $V^{\prime} \mathrm{O}_{2}, \quad V^{\prime} \mathrm{CO}_{2}, \mathrm{HR}$ and breathing pattern were measured; the last $15 \mathrm{~s}$ of each minute were used to perform sniffs (mouthpiece off, mouth closed). $\mathrm{Sa}_{\mathrm{a}} \mathrm{O}_{2}$ was measured throughout exercise.

Recovery. After exercise, the breathing pattern and sniffs were recorded each minute for the first five min and at the $10^{\text {th }}, 15^{\text {th }}, 30^{\text {th }}, 45^{\text {th }}$ and $60^{\text {th }}$ min. The Mueller manoeuvre was performed and arterialized blood samples were obtained starting from the fifth min.

\section{Additional experiments}

On a separate day, four subjects repeated the exercise at SL using cervical magnetic stimulation (CMS) to obtain twitch maximal transdiaphragmatic pressure $(P$ di,tw $)$ and the degree of voluntary neural activation during maximal voluntary efforts by the twitch occlusion technique [17]. Right and left diaphragmatic electromyograms (EMEdi) were obtained using surface electrodes (Ref. 9013L0202; Dantec Medical, Tonsbakken, Denmark) connected to an electromyograph (Mystro+ MS20, Medelec, Woking, Surrey, UK) [18], amplified and band pass filtered (band width $20 \mathrm{~Hz}-$ $5 \mathrm{kHz}$ ).

CMS was performed by a Magstim 200 stimulator equipped with a circular (doughnut shaped) $90 \mathrm{~mm}$ coil with a maximum magnetic field of 2.3 Tesla (Magstim, Whitland, Dyfed, UK) [18, 19]. Stimulation amplitude was $100 \%$ of the maximal output of the stimulator. Supramaximal stimulation was verified according to SimiLowski et al. [19]. Stimuli were delivered at end-expiration with the airways closed.

$P$ di,tw and, consecutively, twitch occlusion were performed firstly $10 \mathrm{~min}$ after end-exercise to avoid twitch potentiation, and then after $60 \mathrm{~min}$ of recovery. 


\section{Data and statistical analysis}

All data are reported as mean \pm SEM. A paired t-test [20] was used to compare data, i.e. maximal WR (WRmax), iso-WR data at SL and HA, and for comparison between $P$ di,max and $P$ di,sniff. One-way analysis of variance (ANOVA) [20] was used for determination of differences in mean values for $P$ di,sniff, lactate and $V^{\prime}$ E during baseline, exercise and recovery, and, when allowed by the F-value, the significance between measures was computed using Fisher's Protected least significant difference (PLSD) test. Significance was set at $\mathrm{p}<0.05$.

\section{Results}

$\mathrm{Sa}_{\mathrm{a}} \mathrm{O}_{2}, \mathrm{~Pa}_{\mathrm{a}} \mathrm{CO}_{2}$, and $\mathrm{pH}$ data are shown in table 1 . At SL, pH became acidotic at WRmax despite the marked hyperventilation (decrease in $\mathrm{Pa}, \mathrm{CO}_{2}$ ). $\mathrm{Sa}, \mathrm{O}_{2}$ remained constant throughout exercise. At $\mathrm{HA}$, all subjects showed hypocapnia and hypoxaemia $\left(\mathrm{S}_{\mathrm{a}}, \mathrm{O}_{2}\right.$ $<90 \%$ ) at baseline; both increased at maximal exercise.

$P$ di,sniff and $P$ oes,sniff were compared to $P$ di,max and $P$ oes,max, respectively, and no difference was found. Therefore only data based on the sniff manoeuvre is reported.

\section{Maximal exercise}

Table 2 shows WR, metabolic parameters, HR, and breathing pattern at maximal exercise. WRmax was similar at SL and HA, even though three subjects reached a lower WR at $\mathrm{HA}$. At SL the subjects reached predicted maximal $V^{\prime} \mathrm{O}_{2}\left(V^{\prime} \mathrm{O}_{2}, \max \right)$ and $\mathrm{HR}$ (HRmax). At HA both $V^{\prime} \mathrm{O}_{2}$,max and $\mathrm{HRmax}$ were lower $(12 \%$ and $6 \%$, respectively), though maximal $V^{\prime} \mathrm{CO}_{2}\left(V^{\prime} \mathrm{CO}_{2}\right.$, max $)$ was similar. $E_{\mathrm{L}}$ was similar at SL and HA (table 1). $R \mathrm{~L}$ was lower at HA compared to SL $(-11 \%$, table 1$)$. The breathing pattern at WR max was similar at SL and HA. Figure 2 a shows average $P$ di,sniff values. $P$ di,sniff was lower at WRmax compared to baseline (SL: average $72 \%$, range $61-80 \%$; HA: average $61 \%$, range $37-80 \%$ ) in all but one test at SL $(94 \%)$. $P$ di,sniff had a positive gastric component ( $P$ di,sniff $\left.>P_{\text {oes,sniff }}\right)$ before exercise in all instances. By contrast, at WRmax, the gastric component of $P$ di,sniff became always negative $(P$ di,sniff $<$ $P$ oes,sniff) at HA, while at SL it was negative in six
Table 2. - Measurements during maximal exercise at sea level and high altitude

\begin{tabular}{|c|c|c|}
\hline Variable & SL & HA \\
\hline WRmax watts & $221 \pm 22$ & $205 \pm 14$ \\
\hline$V^{\prime} \mathrm{O}_{2}, \max \mathrm{mL} \cdot \min ^{-1}$ & $2868 \pm 304$ & $2525 \pm 207 *$ \\
\hline$V^{\prime} \mathrm{O}_{2}, \max \%$ pred & $101 \pm 10$ & $90 \pm 6^{*}$ \\
\hline$V^{\prime} \mathrm{CO}_{2}, \max \mathrm{mL} \cdot \mathrm{min}^{-1}$ & $3411 \pm 387$ & $3142 \pm 257$ \\
\hline HRmax beats $\cdot \min ^{-1}$ & $179 \pm 2$ & $169 \pm 4 *$ \\
\hline HRmax $\%$ pred & $98 \pm 1$ & $93 \pm 2 *$ \\
\hline$V^{\prime} \mathrm{E}, \max \mathrm{L} \cdot \mathrm{min}^{-1}$ & $87.7 \pm 12.3$ & $98.0 \pm 11.6$ \\
\hline$f_{\max }$ breaths $\cdot \min ^{-1}$ & $33.0 \pm 2.3$ & $35.9 \pm 3.1$ \\
\hline$V \mathrm{~T}, \max \mathrm{L}$ & $2.59 \pm 0.26$ & $2.72 \pm 0.25$ \\
\hline
\end{tabular}

Values are mean \pm SEM. WRmax: maximal work rate; $V^{\prime} \mathrm{O}_{2}$,max: maximal oxygen consumption; $V^{\prime} \mathrm{CO}_{2}$, max: maximal carbon dioxide production; HRmax: maximal heart rate; $V^{\prime}$ E,max: minute ventilation during maximal exercise; $f_{\max }$ : breathing frequency during maximal exercise; $V \mathrm{~T}$,max: tidal volume during maximal exercise. *: $\mathrm{p}<0.05 \mathrm{SL}$ versus HA.

subjects and reduced, but still positive in the remaining two. At SL but not at HA $P$ di,sniff recovered to baseline within $60 \mathrm{~min}$.

At SL, Poes,sniff was higher at WRmax (11.34 \pm $0.49 \mathrm{kPa})$ than at baseline $(9.97 \pm 0.39 \mathrm{kPa})$, whereas at $\mathrm{HA}$ it was equal (WRmax: $10.36 \pm 0.78 \mathrm{kPa}$; baseline: $8.99 \pm 0.29 \mathrm{kPa})$. Poes,sniff corr showed similar results at WRmax (SL: 11.24 $\pm 0.39 \mathrm{kPa}$; HA: $10.17 \pm 0.68 \mathrm{kPa}$ ).

At SL, PTPdi averaged $80.74 \pm 9.87 \mathrm{kPa} \cdot \mathrm{s}^{-1}$ over $1 \mathrm{~min}$ at WRmax, all subjects being on or above the fatigue threshold of $53.76-58.65 \mathrm{kPa} \cdot \mathrm{s}^{-1}$ over $1 \mathrm{~min}$ [4]. PTPdi at WRmax was lower at HA than at SL $\left(64.13 \pm 8.21 \mathrm{kPa} \cdot \mathrm{s}^{-1}\right.$ over $\left.1 \mathrm{~min}\right)$, but five subjects were still above and three lay just below the fatigue threshold (42.03-44.97 $\mathrm{kPa} \cdot \mathrm{s}^{-1}$ over $\left.1 \mathrm{~min}\right)$. PTPdi/ PTPoes ratio fell below unity at WRmax both at SL and at HA (but was lower at HA), and recovered to baseline within $5 \mathrm{~min}$ in both conditions (fig. 2b).

At SL, lactate increased from $0.9 \pm 0.1 \mathrm{mEq} \cdot \mathrm{L}^{-1}$ at rest to $6.2 \pm 0.7 \mathrm{mEq} \cdot \mathrm{L}^{-1}$ at the 5 th $\mathrm{min}$ of recovery, regaining baseline at $60 \mathrm{~min}\left(1.0 \pm 0.1 \mathrm{mEq} \cdot \mathrm{L}^{-1}\right)$. At $\mathrm{HA}$, lactate increased from baseline $\left(0.9 \pm 0.1 \mathrm{mEq} \cdot \mathrm{L}^{-1}\right)$ to the 5 th $\mathrm{min}$ of recovery $\left(6.7 \pm 0.6 \mathrm{mEq} \cdot \mathrm{L}^{-1}\right)$ but, as with $P$ di,sniff, lactate did not recover to baseline within $60 \mathrm{~min}\left(1.3 \pm 0.2 \mathrm{mEq} \cdot \mathrm{L}^{-1}, \quad \mathrm{p}<0.05\right)$. In contrast to $P$ di,sniff and lactate, $V^{\prime} \mathrm{E}$ reached baseline $\left(V^{\prime} \mathrm{E}\right.$ at $\mathrm{SL}$ : 12.8 $\pm 1.6 \mathrm{~L} \cdot \mathrm{min}^{-1} ; V^{\prime} \mathrm{E}$ at HA: $\left.15.3 \pm 2.3 \mathrm{~L} \cdot \mathrm{min}^{-1}\right)$ within $15 \mathrm{~min}$ at SL $\left(15.2 \pm 2.4 \mathrm{~L} \cdot \mathrm{min}^{-1}\right)$ and within $30 \mathrm{~min}$ at HA $\left(14.9 \pm 1.5 \mathrm{~L} \cdot \mathrm{min}^{-1}\right)$.

Table 1. - Percentage of $\mathrm{O}_{2}$ saturation of arterial blood $\left(\mathrm{Sa}, \mathrm{O}_{2}\right)$ as estimated by pulse oximetry, arterialized blood $\mathrm{pH}$ and $\mathrm{CO}_{2}$ partial pressure $\left(\mathrm{Pa}_{\mathrm{a}}, \mathrm{CO}_{2}\right)$, dynamic lung elastance $(E \mathrm{~L}$,dyn), and pulmonary resistance $(R \mathrm{~L})$ for normoxic (sea level; $\mathrm{SL})$ and hypoxic (high altitude; HA) exercise

\begin{tabular}{|c|c|c|c|c|}
\hline \multirow{2}{*}{ Variable } & \multicolumn{2}{|c|}{ SL } & \multicolumn{2}{|c|}{ HA } \\
\hline & Baseline & $\operatorname{Max}$ & Baseline & $\operatorname{Max}$ \\
\hline $\mathrm{Sa}_{\mathrm{a}, \mathrm{O}_{2}} \%$ & $96.3 \pm 0.4$ & $96.1 \pm 0.5$ & $87.5 \pm 1.0^{(* *)}$ & $83.0 \pm 0.9^{* *}$ \\
\hline $\mathrm{pH}$ & $7.407 \pm 0.004$ & $7.269 \pm 0.013 * *$ & $7.469 \pm 0.005^{(* *)}$ & $7.327 \pm 0.011^{* *}$ \\
\hline $\mathrm{Pa}_{\mathrm{a}} \mathrm{CO}_{2} \mathrm{kPa}$ & $5.25 \pm 0.13$ & $4.60 \pm 0.25^{* *}$ & $4.59 \pm 0.15^{(* *)}$ & $3.80 \pm 0.17 * *$ \\
\hline$E \mathrm{~L}$, dyn $\mathrm{kPa} \cdot \mathrm{L}^{-1}$ & $0.58 \pm 0.06$ & & $0.65 \pm 0.06$ & \\
\hline$R \mathrm{~L} \mathrm{kPa} \cdot \mathrm{L}^{-1} \cdot \mathrm{s}$ & $0.20 \pm 0.03$ & & $0.18 \pm 0.02$ & \\
\hline
\end{tabular}

Values are presented as mean \pm SEM. Baseline: measurements taken before exercise; Max: measurements taken at maximal exercise. ${ }^{* *}: \mathrm{p}<0.01$ max versus baseline; (baseline at HA versus baseline at SL). 

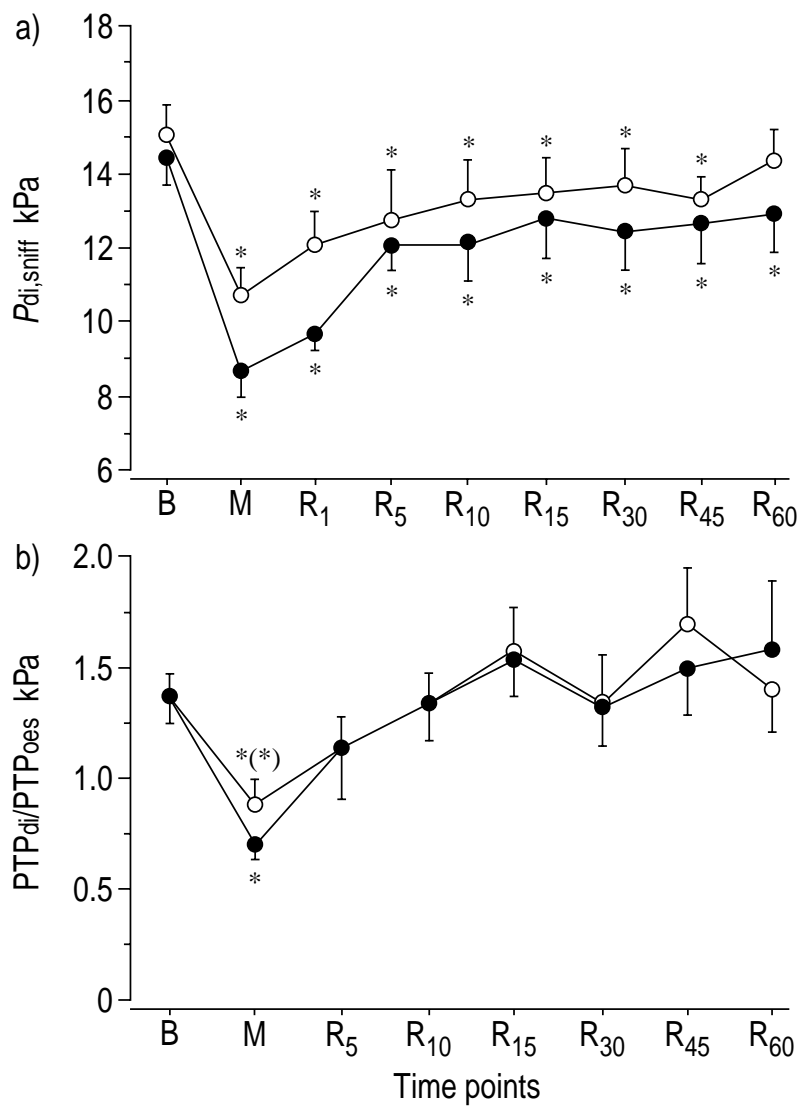

Fig. 2. - Mean \pm SEM of: a) the maximal transdiaphragm pressure $\left(P_{\mathrm{di} i \text { sniff }}\right)$, and of $\left.\mathrm{b}\right)$ the pressure-time product for the diaphragm expressed as a fraction of the oesophageal pressure-time product (PTPdi/PTPoes) at baseline (B), maximal exercise (M), and during $60 \mathrm{~min}$ of recovery (R1-R60) measured at sea level $(\bigcirc)$ and at high altitude (๑). During maximal exercise the PTPdi/PTPoes ratio dropped below unity indicating that the majority of the work of breathing had been shifted from the diaphragm to the accessory inspiratory muscles. *: $\mathrm{p}<0.05$ condition versus $\mathrm{B}$. (sea level versus high altitude)

\section{Isowork rate}

WRmax was lower at HA in three subjects. To data at isowork rate conditions (iso-WR) compared in each subject, WRmax at HA was matched in these three subjects with a similar WR obtained at SL. At iso-WR, $P$ di,sniff was significantly lower at HA (fig. 3a), $P$ oes,sniff never being below baseline (fig. 3b). $V^{\prime} \mathrm{E}$ was higher at HA $\left(117.2 \pm 11.4 \mathrm{~L} \cdot \mathrm{min}^{-1}\right)$ than at iso-WR SL (91.3 \pm $\left.13.3 \mathrm{~L} \cdot \mathrm{min}^{-1}\right)$ because of higher frequency $(35.9 \pm 3.1$ and $30.6 \pm 2.1$ breaths $\cdot \mathrm{min}^{-1}$, respectively, $\left.\mathrm{p}<0.05\right)$. Similar results were obtained for mean inspiratory flow (WRmax HA: 3.64 $\pm 0.41 \mathrm{~L} \cdot \mathrm{s}^{-1}$; iso-WR SL: 3.03 \pm 0.29 $\left.\mathrm{L} \cdot \mathrm{s}^{-1}, \mathrm{p}<0.05\right)$. Notwithstanding the higher $V^{\prime} \mathrm{E}$ at HA, PTPdi and $\mathrm{W}^{\prime}$ di were similar at iso-WR (fig. 4).

\section{Volitional versus objective measurements}

In four subjects retested at SL, both $P$ di,tw and $P$ di,sniff decreased significantly $10 \mathrm{~min}$ after exercise, and recovered $60 \mathrm{~min}$ after exercise (table 3). All subjects showed near complete activation of the
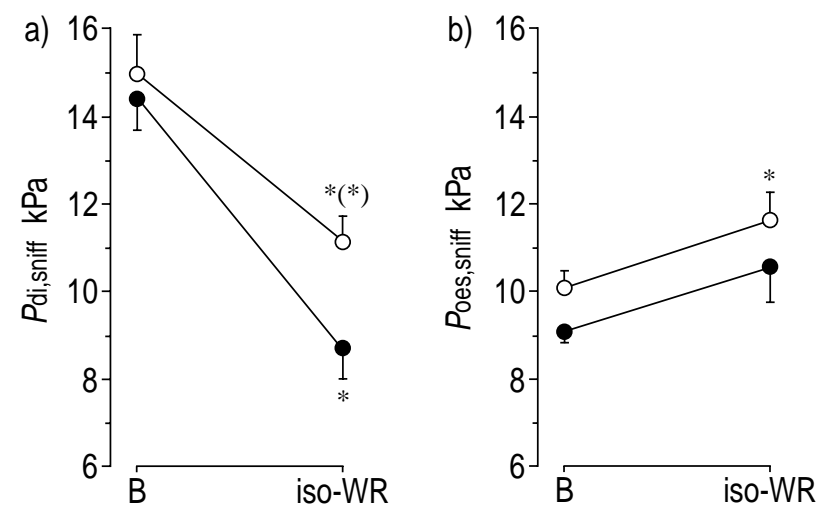

Fig. 3. - Mean \pm SEM of: a) maximal transdiaphragmatic ( $P$ di,sniff $)$

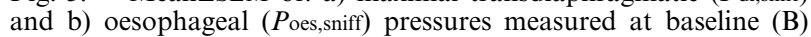
and at isowork rate (iso-WR) at sea level (SL; $\bigcirc$ ) and at high altitude (HA; O). Iso-WR: workload at SL matched to maximal workload reached at HA. The reduction of $P$ di,sniff at iso-WR with respect to baseline was greater at HA. By contrast, $P_{\text {oes,sniff }}$ increased slightly both at SL and HA at iso-WR. *: $\mathrm{p}<0.05 \mathrm{~B}$ versus iso-WR (SL versus HA).

diaphragm, as no significant increase of $P$ di due to CMS was found (fig. 5). Pdi,sniff was similar to $P$ di,max in any condition (fig. 5), showing near complete activation of the diaphragm also with this manoeuvre.

\section{Discussion}

The present data show that diaphragmatic force generating capacity (FGC) at maximal whole-body exercise was impaired at HA compared to equivalent work rates at SL, hypoxia alone being the predominant causative factor. This study also shows that, similarly to endurance exercise [3, 4], exhaustive incremental exercise can produce diaphragm fatigue at both SL and HA.
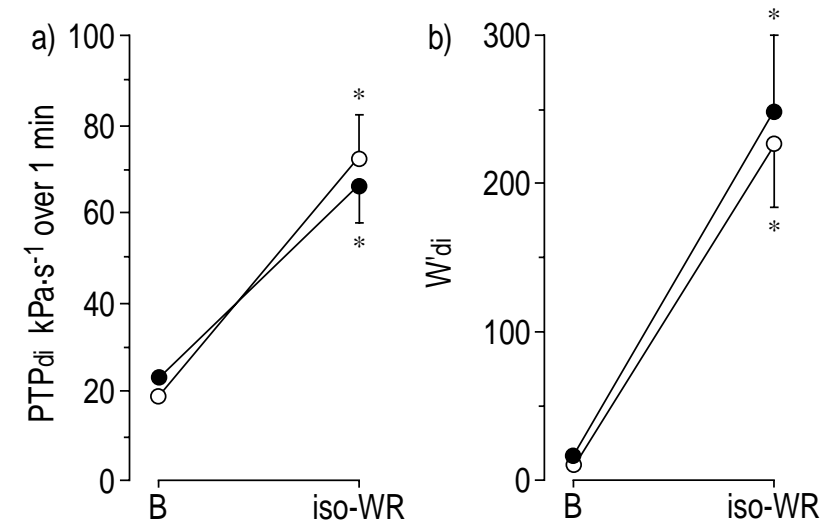

Fig. 4. - Mean \pm SEM of: a) pressure-time product for the diaphragm (PTPdi) and of b) the mechanical work performed by the diaphragm $\left(\mathrm{W}^{\prime} \mathrm{di}\right)$. $\mathrm{W}^{\prime} \mathrm{di}$ is the product of PTPdi and mean inspiratory flow $(V \mathrm{~T} / t \mathrm{I})$. These parameters are shown at baseline (B) and at isowork rate (iso-WR) measured at sea level (SL; $O$ ) and at high altitude (HA; ). Iso-WR: workload at SL matched to maximal workload reached at HA. PTPdi was similar at SL and HA at both B and iso-WR. The same finding applied to $\mathrm{W}^{\prime}$ di which takes into account changes in diaphragm effort induced by flow rate variations. These data indicate that the effort of the diaphragm at iso-WR was similar both at SL and HA. *: $\mathrm{p}<0.05$ B versus iso-WR. 
Table 3. - Volitional and objective measurements of diaphragmatic performance before and after exercise at sea level in four subjects

\begin{tabular}{lrrr}
\hline Variable & Baseline & \multicolumn{1}{c}{$\begin{array}{c}\text { Recovery } \\
10 \text { min }\end{array}$} & $\begin{array}{c}\text { Recovery } \\
60 \text { min }\end{array}$ \\
\hline$P$ di,sniff kPa & $\begin{array}{r}15.15 \pm 0.41 \\
P \text { di,tw kPa }\end{array}$ & $\begin{array}{r}11.09 \pm 0.75^{*} \\
1.41 \pm 0.16^{*}\end{array}$ & $\begin{array}{r}14.23 \pm 0.83 \\
1.78 \pm 0.17\end{array}$ \\
\hline
\end{tabular}

Values are mean \pm SEM. $P$ di,sniff: maximal transdiaphragmatic pressure obtained with a sniff manoeuvre; $P$ di,tw: maximal transdiaphragmatic pressure obtained with supramaximal cervical magnetic stimulation (single twitch). ${ }^{*}: \mathrm{p}<0.005$ condition versus baseline.
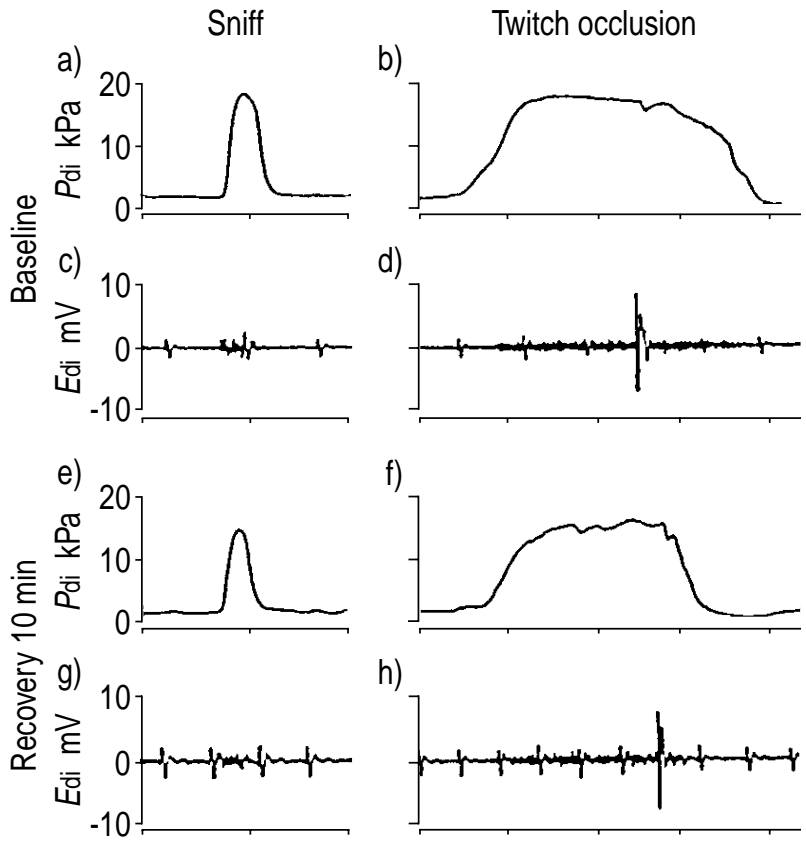

h)
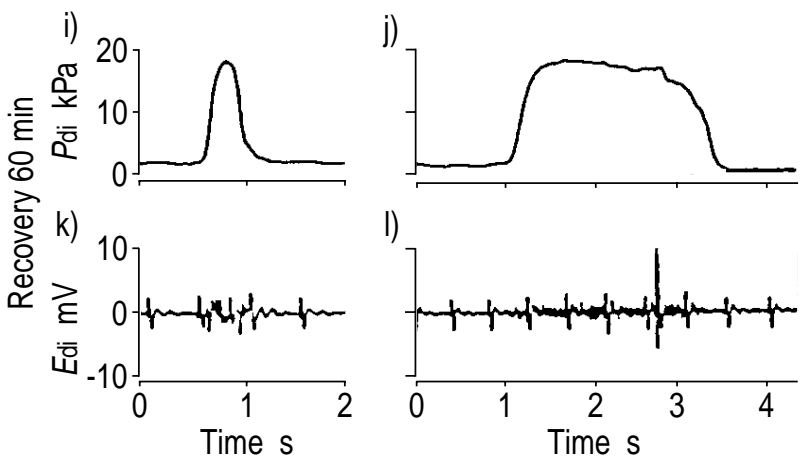

Fig. 5. - Maximal transdiaphragmatic pressure obtained with a "sniff" manoeuvre a, c, e, g, i, k) and with a Mueller manoeuvre to which a single supramaximal twitch was superimposed $(b, d$, $\mathrm{f}, \mathrm{h}, \mathrm{j}, \mathrm{l})$ in a representative healthy subject at rest a-d), at $10 \mathrm{~min}(\mathrm{e}-\mathrm{h})$, and at $60 \mathrm{~min}(\mathrm{i}-\mathrm{l})$ after the end of an exhaustive incremental exercise on cycle-ergometer performed at sea level. Electromyograms of the right hemidiaphragm in response to supramaximal cervical phrenic nerve stimulation (EMEdi) are also provided. The superimposition of supramaximal magnetic stimulation (indicated by the electrical artefact in the EMEdi tracing) on maximal quasistatic efforts never evoked a further increase in maximal transdiaphragmatic pressure. Note that $P$ di obtained with the "sniff" manoeuvre was similar to that obtained during the twitch occlusion test in every condition.

\section{Technical considerations}

BPNS is considered to have the best potential as a diagnostic test [21]. However, the sniff manoeuvre was primarily used because it can be performed during exercise, at variance with BPNS that requires preparation (5-8 $\mathrm{min}$ ) after exercise [3].

Poor subject effort might impair the sniff manoeuvre [21]. All subjects had previous experience in performing the manoeuvre and were very well motivated. Moreover, sniff intrasubject variability was low (mean coefficient of variation at baseline: $2.3 \pm 1.0 \%$, range: $0.1-5.9 \%$ ). Tachypnoea and general exhaustion could limit $P$ di,sniff performance [21]. However, $P$ di,sniff recovered to baseline later than the breathing pattern, both at SL and HA. Furthermore, in contrast to $P$ di,sniff, $P$ oes,sniff did not decrease at maximal exercise, suggesting maximal inspiratory effort even in these extreme conditions.

$P$ di,sniff depends on lung volume [22]. The endexpiratory $P$ oes was monitored to ensure that sniff manoeuvres were performed at similar EELV, endexpiratory $P_{\text {oes }}$ being within $0.15 \mathrm{kPa}$ of baseline just before sniffs in any tested condition. Similar results were obtained with end-expiratory $P$ ga. These data suggest that diaphragmatic length was reasonably constant before $P$ di,sniff manoeuvres.

Finally, according to Travaline et al. [23], Pdi,sniff and $P$ di,max reliability was tested at SL by CMS in a subset of four subjects on a separate day. The trend of $P$ di,sniff decay was similar in the two tests, $P$ di,sniff being within $\pm 5 \%$ at each workload tested. Similarly to $P$ di,sniff, $P$ di,tw was on average $27 \%$ lower than baseline 10 min after exercise (table 3 ), suggesting that $P$ di,sniff was accurate in detecting losses of diaphragm FGC, at least in the condition tested. It was extrapolated that similar results could be obtained at HA.

\section{Diaphragm fatigue}

A decreased diaphragm FGC was found at maximal exercise both at SL and HA, which recovered to baseline late after exercise (fig. 2a), finding that fits the accepted definition of muscle fatigue [21]. These data extend to exhaustive incremental exercise, the evidence that diaphragm fatigue can be generated in normal subjects by endurance exercise [4-6, 24].

At end-exercise, $P$ di,sniff decreased, whereas $P_{\text {oes,sniff }}$ did not or increased compared to baseline (figs. 1 and 3 ). These data are consistent with data obtained at, for example, the first minute of recovery (fig. 1). It may be argued that this observation cannot be explained by fatigue, since both the diaphragm and the extradiaphragmatic muscles serve to reduce the $P$ oes. However, $P$ di,sniff was not only reduced compared to baseline, but it also became lower than $P_{\text {oes,sniff }}$ at end-exercise in almost all the conditions tested (see previously). This suggests diaphragm displacement into the rib cage during maximal manoeuvres, since end-expiratory abdominal pressure $(P \mathrm{ab})$ was close to baseline values at the beginning of the $P$ di,sniff manoeuvre (i.e. abdominal muscles phasically inactive). Finally, prolonged forced muscle contractions (similar to those 
developed by the respiratory muscles during exercise) can cause the phenomenon of potentiation [25]. In this

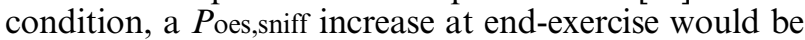
expected, but not a decrease in $P$ di,sniff (rather it should increase too).

The presented finding contrasts with LEVINE et al. [26] who reported, in preliminary experiments, no sign of diaphragmatic fatigue at end-incremental exercise. However, they provided neither references nor data to support their statement. Short incremental exercise may appear too light to produce diaphragm fatigue. However, increased diaphragm work generated by sustained hyperpnoea at rest, comparable to that found in the present study, has been demonstrated to cause significant diaphragm fatigue [4]. Moreover, endexercise $\mathrm{pH}$ and circulating lactate concentrations similar to those found in the present study have been shown to increase the amount of hyperpnoea-induced diaphragm fatigue [4].

Central, transmission and contractile fatigue have been described [10]. In the four subjects in whom the twitch occlusion technique [17] was performed, no signs of central fatigue were detected at least at SL (fig. 5). In the same subjects the M-wave was preserved after exercise, indicating absence of transmission fatigue in the condition tested. Finally, the long lasting duration of $P$ di,sniff decay after exercise at SL and HA (fig. 2), and the postexercise reduction in twitch pressure observed at SL, suggests that contractile fatigue did occur $[3,4,11]$.

\section{Effects of high altitude on diaphragm fatigue}

Incremental exhaustive exercise at $3,325 \mathrm{~m}$ altitude worsened the FGC compared to iso-WR SL (fig. 3) notwithstanding similar effort of the diaphragm (fig. 4). At HA, significant hypoxia was found. Comparable hypoxaemia has been shown to worsen exercise-induced diaphragm fatigue in normobaric conditions [3]. Increased diaphragm work was also found during hypoxic exercise at SL, suggesting that its combination with decreased $\mathrm{O}_{2}$ transport impairs diaphragm FGC in this condition [3]. By contrast, it was found that, although $V^{\prime} \mathrm{E}$ was higher at HA than at iso-WR SL, PTPdi as well as $\mathrm{W}^{\prime}$ di (fig. 4) and PTPoes were equal, indicating that in the experimental condition hypoxia per se hastened exercise-induced diaphragm fatigue.

EELV changes affect inspiratory muscle effort estimation [13]. EELV was not directly assessed, but it is generally accepted that in young healthy subjects it does not exceed its baseline value during exercise [27]. Conversely, the lower density of the air at HA (resulting in decreased airway flow resistance) could explain the increased inspiratory muscle efficiency in generating $V^{\prime} E$ [7]. Indeed, similarly to previous studies [7], $R \mathrm{~L}$ decreased at HA approaching predicted values [28].

Not only did hypoxia impair independently exerciseinduced diaphragm fatigue at HA, but it also influenced respiratory muscle interaction during exercise. AlIVERTI et al. [29] have shown that rib cage and abdominal muscles are progressively activated during exercise, allowing the diaphragm to act as a flow generator. Similar results were obtained in the present study at SL.
Indeed, PTPdi/PTPoes ratio fell below unity at maximal exercise, indicating a strong activation of extra-diaphragmatic respiratory muscles (fig. 2b). At HA, endexercise PTPdi/PTPoes ratio (fig. 2b) as well as absolute values of PTPdi significantly decreased compared to SL, suggesting further recruitment of accessory respiratory muscles to assist impending failure of the diaphragm. These observations are indirectly confirmed by studies on hyperoxic exercise that showed a decrease of accessory muscle activation compared to normoxic exercise [24].

At $\mathrm{HA}$, but not at SL, diaphragm recovery from fatigue took longer than $60 \mathrm{~min}$ (fig. 2a). It was associated with lower (three subjects) or equal (five subjects) external work at HA, with significantly reduced end-exercise PTPdi, and with blood lactate higher than baseline $60 \mathrm{~min}$ after exercise. As lactate clearance is delayed by hypoxia [30], and the increased level of circulating lactate and other metabolites has been implicated in the fatigue process [31], it might well be that hypobaric hypoxia and not increased workload, represents the major cause of the delay in recovery from exercise-induced diaphragm fatigue at HA.

In conclusion, exercise at high altitude challenges the respiratory muscles as a whole. In fact, not only can high altitude enhance diaphragm fatigue during exhaustive incremental exercise, but it also overloads accessory inspiratory muscles on account of hypobaric hypoxia alone, at least during acute exposure to the altitude tested. Whether this could affect exercise capability, particularly when ventilatory requirements become enormous (e.g. in acclimatized subjects at extreme altitudes), is still questionable. In fact, the effects of hypoxaemia are not confined to the respiratory muscles, since changes in oxygen supply affect locomotor muscles as well [24]. Further work is required to assess whether exercise-induced diaphragm dysfunction has any role in determining exercise limitation at high altitude.

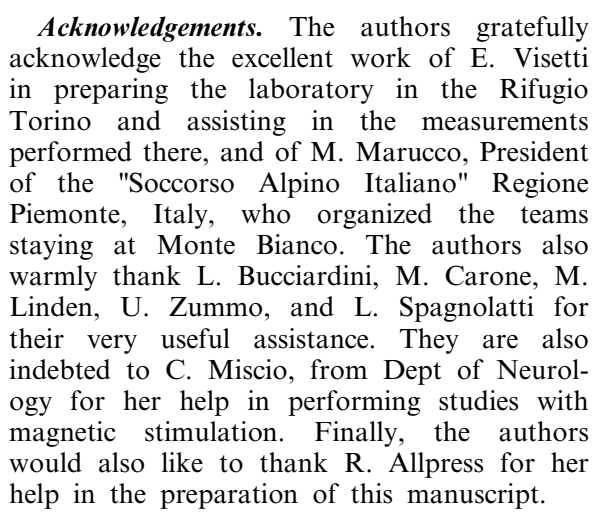

References

1. Houston CS, Sutton JR, Cymerman A, Reeves JT. Operation Everest II: Man at extreme altitude. $J$ Appl Physiol 1987; 63: 877-882.

2. West JB, Boyer SJ, Graber DJ, et al. Maximal exercise 
at extreme altitudes on Mount Everest. J Appl Physiol 1983; 55: 688-698.

3. Babcock MA, Johnson BD, Pegelow DF, Suman OE, Griffin D, Dempsey JA. Hypoxic effects on exerciseinduced diaphragmatic fatigue in normal healthy humans. J Appl Physiol 1995; 78: 82-92.

4. Babcock MA, Pegelow DF, McClaran SR, Suman OE, Dempsey JA. Contribution of diaphragmatic power output to exercise-induced diaphragm fatigue. $J \mathrm{Appl}$ Physiol 1995; 78: 1710-1719.

5. Babcock MA, Pegelow DF, McClaran SR, Suman OE, Dempsey JA. Exercise-induced diaphragmatic fatigue in healthy humans. J Physiol (Lond) 1993; 460: 385 405.

6. Mador MJ, Magalang UJ, Rodis A, Kufel TJ. Diaphragmatic fatigue after exercise in healthy human subjects. Am Rev Respir Dis 1993; 148: 1571-1575.

7. Gautier H, Peslin R, Grassino A, et al. Mechanical properties of the lungs during acclimatization to altitude. J Appl Physiol 1982; 52: 1407-1415.

8. Appendini L, Purro A, Patessio A, et al. Partitioning of inspiratory muscle workload and pressure assistance in ventilator-dependent COPD patients. Am J Respir Crit Care Med 1996; 154: 1301-1309.

9. Sato J, Davey BLK, Shardonofsky F, Bates JHT. Low-frequency respiratory system resistance in the normal dog during mechanical ventilation. $J$ Appl Physiol 1991; 70: 1536-1543.

10. Tobin MJ, Laghi F. Monitoring of respiratory muscle function. In: Tobin MJ, ed. Principles and practice of intensive care monitoring. $1^{\text {st }}$ ed, New York, McGrawHill Inc, 1998; 497-544.

11. Laghi F, D' Alfonso N, Tobin MJ. Pattern of recovery from diaphragmatic fatigue over 24 hours. $J$ Appl Physiol 1995; 79: 539-546.

12. Kyroussis D, Polkey MI, Keilty SEJ, et al. Exhaustive exercise slows inspiratory muscle relaxation rate in chronic obstructive pulmonary disease. Am J Respir Crit Care Med 1996; 153: 787-793.

13. Collett PW, Perry C, Engel LA. Pressure-time product, flow, and oxygen cost of resistive breathing in humans. J Appl Physiol 1985; 58: 1263-1272.

14. McLoughlin P, Popham P, Linton RAF, Bruce RCH, Band DM. Use of arterialized venous blood sampling during incremental exercise tests. J Appl Physiol 1992; 73. 937-940.

15. Wasserman K, Hansen JE, Sue DY, Whipp BJ, Casaburi R. Principles of Exercise Testing and Interpretation. $2^{\text {nd }}$ ed, Malvern, Lea \& Febiger, 1994; $1-479$.

16. Quanjer PH. Standardized Lung Function Testing. Report Working Party. Standardization of Lung Function Tests. European Community for Coal and Steel. Bull Eur Physiopathol Respir 1983; 19: Suppl. 5, $1-82$.

17. Similowski T, Duguet A, Straus C, Attali V, Boisteanu
D, Derenne JP. Assessment of the voluntary activation of the diaphragm using cervical and cortical magnetic stimulation. Eur Respir J 1996; 9: 1224-1231.

18. Similowski T, Fleury B, Launois S, Cathala HP, Bouche P, Derenne JP. Cervical magnetic stimulation: a new painless method for bilateral phrenic nerve stimulation in conscious humans. J Appl Physiol 1989; 67: 1311-1318.

19. Similowski T, Mehiri S, Duguet A, Attali V, Straus C, Derenne JP. Comparison of magnetic and electrical phrenic nerve conduction time. J Appl Physiol 1997; 82: 1190-1199.

20. Colton T. Statistic in Medicine. $1^{\text {st }}$ edn. Boston, Little Brown and Company, Inc, 1974; 1-189.

21. NHLBI Workshop. Respiratory muscle fatigue: report of the respiratory muscle fatigue workshop group. $\mathrm{Am}$ Rev Respir Dis 1990; 142: 474-480.

22. Wanke T, Schenz G, Zwick H, Popp W, Ritschka L, Flicker M. Dependence of maximal sniff generated mouth and transdiaphragmatic pressures on lung volume. Thorax 1990; 45: 352-355.

23. Travaline JM, Sudarshan S, Criner GJ. Recovery of PdiTwitch following the induction of diaphragm fatigue in normal subjects. Am $J$ Respir Crit Care Med 1997; 156: 1562-1566.

24. Bye PTP, Esau SA, Walley KR, Macklem PT, Pardy RL. Ventilatory muscles during exercise in air and oxygen in normal men. $J$ Appl Physiol 1984; 56: 464 471 .

25. Wragg S, Hamnegard C, Road J, et al. Potentiation of diaphragmatic twitch after voluntary contraction in normal subjects. Thorax 1994; 49: 1234-1237.

26. Levine S, Henson D. Low frequency diaphragmatic fatigue in spontaneously breathing humans. $J \mathrm{Appl}$ Physiol 1988; 64: 672-680.

27. Beck KC, Staats BA, Hyatt RE, Babb TG. Dynamics of breathing during exercise. In: Whipp BJ, Wasserman K, eds. Lung biology in health and disease. Exercise: pulmonary physiology and pathophysiology. New York, Marcel Dekker Inc, 1991; 67-97.

28. Varene P, Timbal J, Jacquemin C. Effect of different ambient pressures on airway resistance. J Appl Physiol 1967; 22: 699-706.

29. Aliverti A, Cala SJ, Duranti R, et al. Human respiratory muscle actions and control during exercise. J Appl Physiol 1997; 83: 1256-1269.

30. Wasserman K, Beaver WL, Davis JA, Pu J, Heber D, Whipp BJ. Lactate, pyruvate, and lactate-to-pyruvate ratio during exercise and recovery. J Appl Physiol 1985; 59: 935-940.

31. McLaren DPM, Gibson H, Parry-Billings M, Edwards RHT. A review of metabolic and physiological factors in fatigue. In: Pandolf $\mathrm{KB}$, ed. Exercise and Sport Science Reviews. Vol.17, Baltimore, Williams \& Wilkins, 1989; 29-66. 